\title{
Analysis of Spatiotemporal Distribution and Influencing Factors of Grassland Fire in China-Mongolia Border Regions in Recent 15 Years
}

\author{
Yulong Bao ${ }^{1,2}$, Yinshan ${ }^{2}$, Lina $^{1}$, Narisu \\ ${ }^{1}$ College of Inner Mongolia normal university geography science,Hohhot 010020, China; \\ ${ }^{2}$ Inner Mongolian key laboratory of remote sensing and geographic information system,Hohhot 010020, China \\ 近 15 年中蒙边境地区草原火时空分布及影响因子分析 \\ 包玉龙 ${ }^{1,2}$ 银山 $^{2}$ 丽娜 $^{1}$ 那日苏 ${ }^{1}$ \\ ${ }^{1}$ 内蒙古师范大学地理科学学院, 呼和浩特 010020 , 中国 \\ ${ }^{2}$ 内蒙古自治区遥感与地理信息系统重点实验室, 呼和浩特 010020, 中国
}

\begin{abstract}
In view of the grassland fire occurred in 3 banner of East Ujimqin banner in China and adjacent Mongolia as research area, the spatiotemporal characteristics was analyzed by GIS space analysis method and using the 2000-2014 MCD45A burned products, MOD13Q1 products data and meteorological data.The results indicated that recent $15 y$ year, the burned area distributed widly and $95 \%$ of the total area of the study area located in the territory of Mongolia, with the highest rate of 7 in Khalkhgol . But East Ujimqin Banner has not happened it. The annual variation trend of the burned area showed that the downward trend happened in $2000-2008$, and upward trend in 2008 - 2014.Known by analysis of influencing factors of grassland fire that large burned area and high frequency in high NDVI area, opposite in lower NDVI area; The interannual burned area variation with precipitation has inversely proportional,with temperature has direct proporation.
\end{abstract}

Keywords: Grassland Fire;Influencing factor; ChinaMongolia Border

\section{摘要}

利用 GIS 空间分析方法, 采用 2000-2014 年 MCD45A 火烧迹地数据、NDVI 产品数据 MOD13Q1 以及气象数 据, 通过分析内蒙古东乌珠穆沈旗及与该旗接壤的蒙 古国哈拉哈郭勒、额尔德尼查干及马塔德三个苏木

通讯邮址: 包玉龙, E-mail: baoyulong@imnu.edu.cn.
2000-2014 年草原火时空分布规律和植被覆盖、气候 特征因子对草原火时空分布的影响。结果表明: 近 15 年研究区过火迹地总面积 $7.99 \times 10^{3} \mathrm{~km}^{2}$, 其中蒙 古国境内的过火迹地面积 $7.68 \times 10^{3} \mathrm{~km}^{2}$, 占总过火 面积的 95\%; 最高过火频次在蒙古国的哈拉哈郭勒苏 木境内, 频次为 7。2000-2014 过火面积的年际变化 表明, 过火面积呈减少后增长趋势, 2008 达到最小 值。从分析草原火影响因子来看, NDVI 高的区域过 火面积和过火频次高, NDVI 较低的区域则相反; 火 烧迹地面积的年际变化与降水量年际变化呈反比, 与 气温呈正比。

关键词: 草原火; 影响因子; 中蒙边境

\section{1. 引言}

草原火灾作为自然生态系统中重要的干扰因子之一, 在全球范围内频繁发生 ${ }^{[1-2]}$ 。其中, 中蒙边境地区则 是发生草原火灾极为频繁的区域。加之研究区的春秋 两季降水量少、天气干燥、大风日多, 并且大部分草 原人烟稀少, 交通不便, 因此在关于用火管理方面难 度较大, 草原火灾时有发生, 对国家及人民生命财产 造成了较为严重的损失 ${ }^{[3]}$ 。过火之处部分植被所剩无 几, 植物种类数量以及生物量大减, 甚至一些分布区 域较窄的物种濒临灭绝。因此, 火灾对脆弱的草原生 态系统起到直接作用, 容易引起草原生态平衡的破 坏。

不同的气候状况与不同的植被类型和草原火时 空分布相适应, 这使得草原火的时空格局及其气候变 化关系成为科研界和政府部门的热点 ${ }^{[4]}$ 。目前, 随着 空间统计学和地理信息技术的迅速发展, 诸多国内外 研究者对草原火行为时空分布特征与影响因子进行 
Risk Analysis and Crisis Response in Big Data Era (RAC-16)

了深入的探索与研究。并草原火灾给国家造成巨大的 经济损失的同时也影响到边境地区的和谐发展与社 会稳定, 甚至涉及到国际火情的防治问题。因此, 对 中蒙边境地区草原火时空分布及影响因子分析是具 有重要的科学意义以及为两国对草原火灾风险预测 和防治提供有效的科学依据。

\section{2. 材料与方法}

\section{1 . 研究区概况}

研究区处于蒙古高原中部 (图 1), 典型大陆性气候温 带典型草原区的蒙古国哈拉哈郭勒、额尔德尼查干及 马塔德三个苏木和内蒙古东乌珠穆沈旗, 全年季相更 替明显, 大风日多, 冬季寒长干燥, 夏季雨热同期 ${ }^{[5]}$ 。 一月平均气温在 $-18 \sim-22^{\circ} \mathrm{C}$, 七月平均气温在 $19 \sim$ $22^{\circ} \mathrm{C}$, 年降水量为 $200 \sim 300 \mathrm{~mm}$ 。

研究区的草原区面积广大、人口稀少、草高、草
NDVI 数据是从 MODIS 网站中获取的 MOD13Q1 产 品数据, 蒙古国三个苏木的气象数据是由内蒙古师范 大学遥感与地理信息重点实验室提供的, 内蒙古东乌 珠穆沁旗的气象数据是从中国气象数据共享服务网 站上免费下载的。

\section{3. 研究方法}

利用 MRT (Modis Reprojection Tool) 工具, 对近 15 年的 MCD 45A 火烧迹地数据及 MOD $13 Q 1$ 数据进行投 影转换、拼接等预处理。再利用研究区的矢量裁剪出 整个研究区的过火面积、过火频次以及 NDVI 值。通 过传统的统计方法统计出火烧迹地面积、火烧发生频 率以及各气象数据, 再利用地理信息空间分析方法分 析研究区的火烧迹地时空分布特征、火灾发生次数和 过火面积的年际变化与研究区的植被覆盖、降水量、 气温等自然因素之间的相关关系。

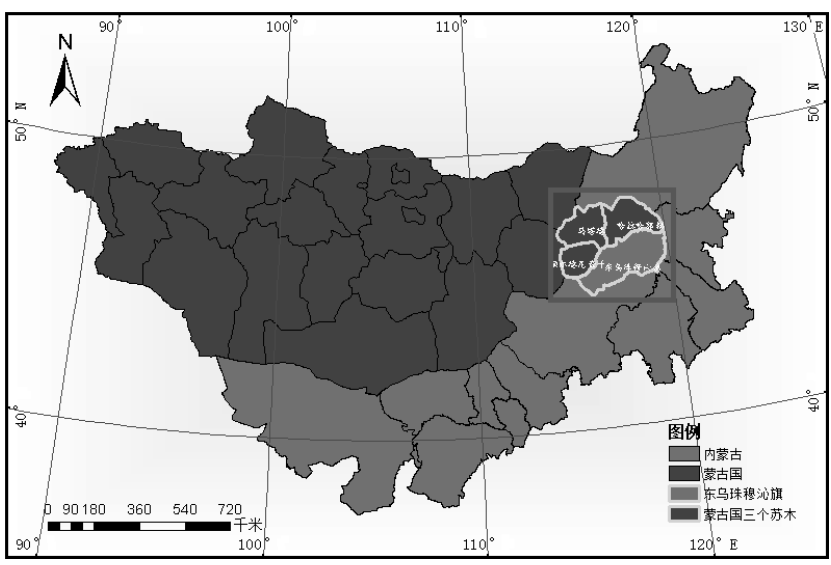

图 1. 研究区地理位置图

厚, 地面单位面积可燃物量多, 尤其春秋两季干早、 多风、日照强 ${ }^{[6]}$ 等气候自然条件为草原火灾频繁发生 具备了客观条件。成为蒙古高原草原火灾情况最为严 重的地区之一。

\section{2. 数据来源}

所利用的 MCD $45 \mathrm{~A}$ 数据是空间分辨率为 $500 \mathrm{~m}$ 的旬 产品数据, 是 MODIS 陆地产品 5 系列中的一款, 中分 辨率成像光谱仪 (MODIS 传感器) 的火烧迹地面积产 品。从 USGS 的 LPDAAC (Land processes distributed active archive center) 中可免费下载 ${ }^{[7-8]}$ 。对于大 多数用户来说与其有关的数据是火烧迹地的位置和 燃烧的日期。

\section{3. 结果与分析}

\section{1. 中蒙边境地区过火迹地的空间分布}

图 2 是中蒙边境地区 2000-2014 年间过火迹地 的空间分布特征, 从图中可以看出过火迹地主要分布 在蒙古国境内。然而近 15 年来, 整个研究区总过火 迹地面积为 $7.99 \times 10^{3} \mathrm{~km}^{2}$, 其中东乌珠穆沈旗的过火 迹地为 $408.742 \mathrm{~km}^{2}$, 蒙古国境内的过火迹地面积 $7.68 \times 10^{3} \mathrm{~km}^{2}$, 占总过火面积的 $95 \%$ 。并且过火频次 最高的地区, 主要分布在蒙古国境内的哈拉哈郭勒、 马塔德与哈拉哈郭勒的边境上, 过火频次达到 15 年 内同一个像元上发生 7 次, 但分布面积较小; 过火频 次最低的地区则散布在整个研究区中, 虽然这是过火 
Risk Analysis and Crisis Response in Big Data Era (RAC-16)

迹地分布面积最广的频次, 但也可直接看出我国境内 的过火面积是最小的, 其频次为 $1 \sim 2$ 次。

东乌珠穆沈旗的过火迹地频繁出现在与蒙古国 交界的北部地区, 是沿着两国边境线蔓延着。这可能 是由蒙古国越境火灾引起的东乌珠穆沈旗北方出现 过火迹地, 说明蒙古国越境火灾的风险比较大。

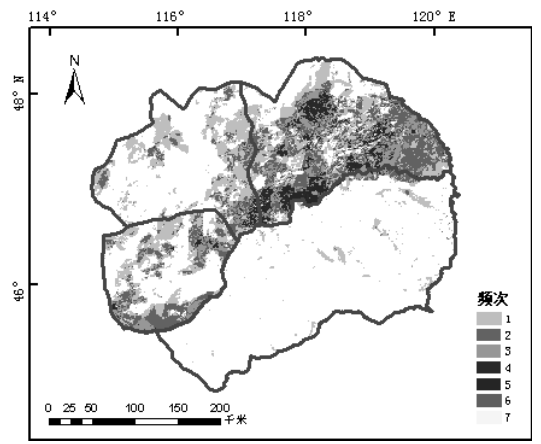

图 2. 2000-2014 年研究区过火迹地空间分布

\section{2. 中蒙边境地区过火迹地的时间分布}

图 3 表示 2000-2014 年中蒙边境地区过火迹地 面积的年际变化, 根据图 3 可看出近 15 年内, 研究 区过火迹地面积存在明显的年际变化差异。图中 2000、2003、2004、2011、2012、及 2014 年的过火 迹地面积都相当高, 面积分别为 $1025.4 \mathrm{~km}^{2}$ 、 1017. $24 \mathrm{~km}^{2} 、 950.36 \mathrm{~km}^{2} 、 866.9 \mathrm{~km}^{2} 、 1123.9 \mathrm{~km}^{2}$ 及 $1112.1 \mathrm{~km}^{2}$ 。而 2002 年与 2008 年的过火面积小, 分 别为 $15.8 \mathrm{~km}^{2} 、 17.5 \mathrm{~km}^{2}$ 。对上数据的分析来看, 中 蒙边境地区的过火迹地面积的年际变化看似随机性, 但大体呈现出 2000-2008 年减少趋势, 2008-2014
年增加趋势的规律性。中国境内与蒙古国境内的过火 迹地面积差异大。并且每年的蒙古国境内的过火迹地 面积占研究区总过火迹地面积的 $90 \%$ 以上, 甚至是有 些年达到了 99\%。因此, 蒙古国境内的火烧对于整个 研究区火烧起着决定性的作用。由每个区域的过火面 积年际变化趋势可看出研究区内的蒙古国境内的过 火迹地面积越大的年份中国境内的过火面积也相比 其余年的要大, 所以更能进一步说明蒙古国越境火灾 的可能。

\section{3. 中蒙边境地区草原火影响因子分析}

\subsection{1. 植被覆盖}

可燃物存量是影响草原火灾发生与发展的首要 因子 ${ }^{[9]}$ 。图 4 是研究区的 NDVI 分布图, 从过火迹地 的空间布图与 NDVI 的空间分布图对比来看, 蒙古国 哈拉哈郭勒的 NDVI 相对与其他两个苏木的 NDVI 要 高, 说明哈拉哈郭勒苏木的植被覆盖度大, 并且从过 火分布图来看, 哈拉哈郭勒的过火面积是最大的, 并 且分布着高频次的过火迹地。除东乌珠穆沈旗东北部 以及与其连接的蒙古国哈拉哈郭勒西南部地区由于 树林较多而引起的 NDVI 较大地区的过火频次较低以 外, 其余的为 NDVI 分布与过火迹地分布以及频次成 正比。这表明, 植被覆盖度越高, 火烧几率越高, 过 火频次也越高。从图中可以知道东乌珠穆沈旗的 NDVI 也很高, 但是过火面积很小, 这正是进一步证 明了境外火造成的东乌珠穆沈旗的草原火。

\subsection{2. 气候特征}

图 5 (A) 是蒙古国额尔德尼查干苏木的近 15 年 的过火面积、降水量及气温的年际变化趋势对比图, 图中显示 2002 年的降水量为最高, 年降水量达

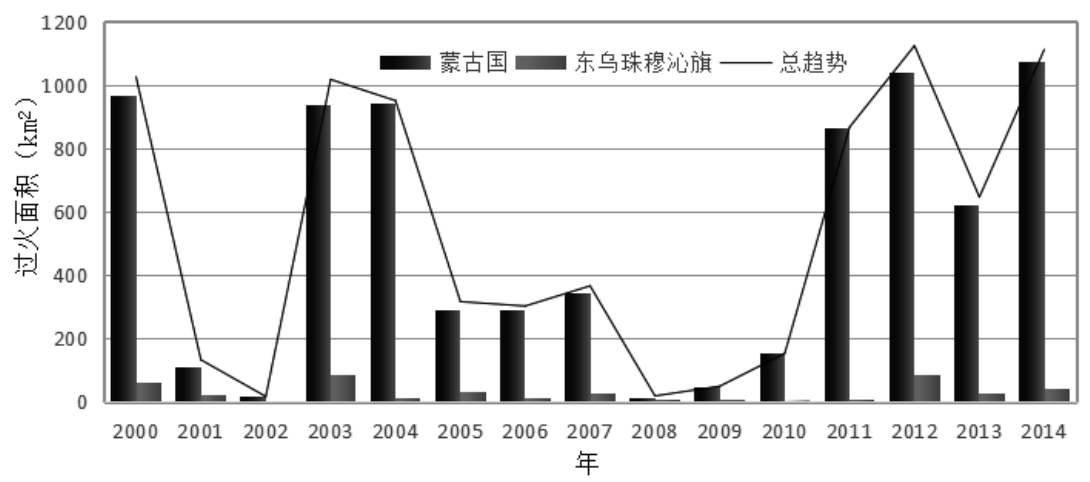

图 3. 2000-2014 年中蒙边境地区过火迹地面积的年际变化趋势 
Risk Analysis and Crisis Response in Big Data Era (RAC-16)

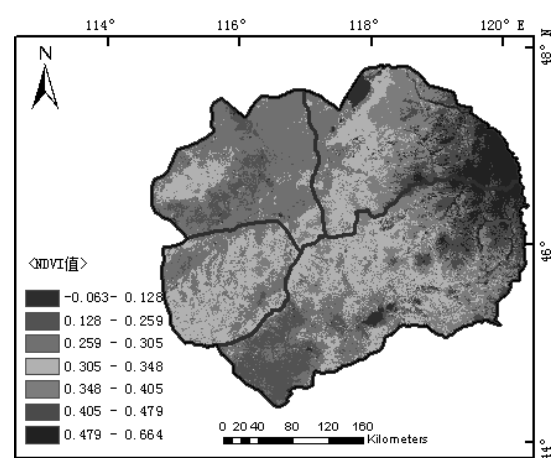

图 4. 2000-2014 年中蒙边境地区年均 NDVI 值空间分布

到 $337 \mathrm{~mm}$, 而过火面积则较小, 为 $152.99 \mathrm{~km}^{2}$; 而 2004 年的过火面积达 $2525.856 \mathrm{~km}^{2}$, 是过火面积最高的一 年, 但降水量则不是很高, 达到 $242.200 \mathrm{~mm} ; 2008$ 年与 2012 年的降水量较高, 分别为 $275 \mathrm{~km}^{2}$ 和 $344.5 \mathrm{~km}^{2}$ ，但过火面积则小，分别为 $10.25 \mathrm{~km}^{2}$ 和 $55.3 \mathrm{~km}^{2}$ 。图 5 (B) 是蒙古国马塔德过火面积、降水 量及气温的年际变化趋势对比图, 2002 年的降水量 与 2002 年的过火面积成反比, 气温是高峰值, 而过 火面积是低谷值; 气温的波动曲线与过火面积的波动 曲线呈相似性。图 5(C) 是蒙古国哈拉哈郭勒的过 火面积、降水量及气温的年际变化趋势对比图, 从曲 线图中可以看出, 此图并不与前两图的规律一致, 而 是过火面积与降水量的曲线相似, 却与气温的曲线呈 反比, 但此种现象的出现与哈拉哈郭勒苏木的 NDVI 与其他蒙古国的两个苏木相对要高, 因此主要受植被 覆盖的影响较多引起的。图 5 (D) 是内蒙古东乌珠 穆沈旗的过火面积、降水量及气温的年际变化趋势对 比图, 可知过火曲线与降水曲线成反比, 但气温与过
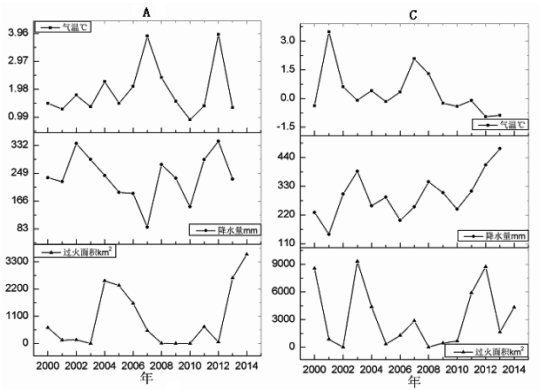

火面积的曲线大体上相似, 呈正比。

\section{4. 结论}

采用 GIS 空间分析方法对中蒙边境地区 2000_2014 共 15a 的 MCD45A 火烧迹地产品进行分析研究。通过 分析获得中蒙边境地区草原火的空间分布、发生频 率、发生次数和过火面积的年际和年内变化及草原火 在中蒙两国境内的差异等特征。研究结果表明:

1）中蒙边境地区草原火空间分布具有明显的规 律性, 无论是过火迹地的分布或频次, 都主要集中分 布在研究区中的蒙古国境内, 特别是分布在蒙古国的 哈拉哈郭勒苏木。次之为马塔德以及额尔德尼查干苏 木。并且每个像元上的过火频次较高, 最高在蒙古国 的哈拉哈郭勒苏木境内, 过火频次达到 $15 \mathrm{a}$ 内同一个 像元上发生 7 次。而中国的东乌珠穆沁旗境内却没有 该现象。

2）从过火迹地的年际变化看出, 2000-2014 年 间整个研究区呈现出 2000-2008 年减少趋势, 而 2008-2014 年具有增加趋势。两个不同境内的区域对 比分析结果表明, 蒙古国的过火迹地面积远大于东乌 珠穆沈旗, 研究区总过火面积的 95\%分布在蒙古国境 内, 是决定研究区过火面积的最主要部分。

3) 从分析草原火影响因子来看, NDVI 高的区域 过火面积和过火频次高, NDVI 较低的区域则相反; 火烧迹地面积的年际变化与降水量年际变化呈反比, 与气温呈正比。

\section{5. 讨论}

本文从中蒙边境地区选取典型区, 分析了中蒙边境地 区近 15 年草原火时空变化及其植被、气温、降水的 影响。MCD45A 数据提供给用户各种质量评估信息和

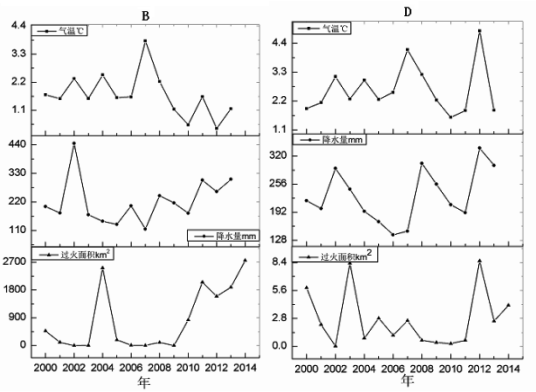

图 5. 2000-2014 年过火面积、降水量及气温的年际变化趋势对比 
Risk Analysis and Crisis Response in Big Data Era (RAC-16)

每个像素的质量评估得分, 能够预计研究区内总过火 面积。对于大多数用户来说与其有关的数据是火烧迹 地的位置和燃烧的日期。因此, 利用该数据进行草原 火时空分布的研究是对火烧的位置和火烧的时间上 的准确率是高的。本论文所分析的影响因子植被覆 盖、降水量与气温对草原火的影响结果与雒瑞森 (2013) 的, 曲炤鹏 (2010) 等的研究结果一致。植被状 况是影响草原火空间分布的主要特征因素, 而气候因 子 (尤其是降水) 对草原火的时间动态具有重要影响 [10]。从研究区过火区的空间分布以及 Chuvieco 等在 火行为的影响因子分析中, 将全球火区组与人文因子 之间建立关系。他们发现单位面积 GDP 较低的区域与 高的火密度的年间变异有关。经济情况越好的区域, 火密度的年间变异越小且持续更长 ${ }^{[11]}$ 。因此看来, 影 响草原火的影响因素更为多样, 除自然影响因素外, 人文因素也是不容忽视的。本论文只选取自然因素的 影响分析, 缺少人文因素的分析, 因而在研究草原火 影响因子中分析人文因素的影响也是今后研究的重 点之一。火行为作为草原生态系统的自我调节措施, 对草原生态系统的平衡和稳定起着重要作用 ${ }^{[10]}$ 。因 此, 调整火灾管理政策, 维持草原生态系统的可持续 发展是很重要的。

\section{Acknowledgements}

This study was supported by National Natural Science Foundation of China (No.61550005) and National Natural Science Foundation of China (No.41561099) and Natural Science Foundation of Inner Mongolia (No.2015BS0505).

\section{致谢}

本研究得到了资助项目: 国家自然科学基金 (61550005) 和国家自然科学基金（41561099）和内 蒙古自然科学基金（2015BS0505）的支撑。

\section{参考文献}

[1] 雒瑞森. 全球火格局的时空变异及其机理分析. 杭
州: 浙江大学, 2013

[2] 张正祥,张洪岩,李冬雪, 等.呼伦贝尔草原人为火 空间分布格局.生态学 2013,33(7):2023 2031

[3] 陈世荣.草原火灾遥感监测与预警方法研究.北京: 中国科学院遥感应用研究所,2006

[4] W.J. Bond, J.E. Keeley. Fire as a global 'herbivore': the ecology and evolution of flammable ecosystems. Trend in Ecology \& Evolution. 2005, 20: $387 \sim 94$

[5] 宝音.蒙古学百科全书(地理). 呼和浩特: 内蒙古人 民出版社,2011:180 376

[6] 乌云德吉,包玉海,包玉龙,等.东乌珠穆沈草原火 源指数遥感分析, 中国灾害防御协会风险分析 专业委员会第六届年会论文集,2014

[7] 张海军,齐曙光.基于 MODIS 数据的 2002-2012 年 河南省火灾时空特征分析. 河北师范大学学 报,2015,39(4),352 358

[8] Boschetti L, Roy D P, Justice C O, et al. Global assess-ment of the temporal reporting accuracy and precision ofthe MODIS burned area product $[\mathrm{J}]$. International Journal of Wildland Fire ,2010, 19(6): 705 709.

[9] Y. Zhuo, G.X. Liu, F.M. Yu. The combustible materials remote sensing ration calculation and fire risk dynamic. Journal of Risk Analysis and Crisis Response, 2011, 1(1):65-74

[10] 曲炤鹏,郑淑霞,白永飞,等. 蒙古高原草原火行为 的时空格局与影响因子. 应用生态学报, 2010,21(4):807-813

[11] E. Chuvieco, L. Ciglio, C. Justice. Global characterization of fire activity: toward defining fire regimes from Earth observation data. Global Change Biology, 2008,14:1488 502 